\title{
Modeling the Exchange Rate Volatility Using the BRICS GARCH-type Models
}

\author{
Lebotsa Daniel Metsileng ${ }^{1}$, Ntebogang Dinah Moroke ${ }^{2} \&$ Johannes Tshepiso Tsoku $^{1}$ \\ ${ }^{1}$ Department of Business Statistics and Operations Research, North West University, Mafikeng Campus, South \\ Africa \\ ${ }^{2}$ Faculty of Economic and Management Sciences, North West University, Mafikeng Campus, South Africa \\ Correspondence: Johannes Tshepiso Tsoku, Associate Professor, Department of Business Statistics and Operations \\ Research, North West University, Mafikeng Campus, South Africa.
}

Received: July 23, 2021

Accepted: August 30, 2021

Online Published: October 11, 2021

doi:10.5430/ijfr.v12n5p166

URL: https://doi.org/10.5430/ijfr.v12n5p166

\begin{abstract}
The paper models the performance of GARCH-type models on BRICS exchange rates volatility. The levels of interdependence and dynamic connection among the BRICS financial markets using appropriate univariate time series models were evaluated for the period January 2008 to January 2018. The results revealed the presence of $\mathrm{ARCH}$ effects in the BRICS exchange rates. The univariate GARCH models for the BRICS exchange rates were fitted to the data using Student t-distribution. The GARCH $(1,1)$ model found the unconditional volatility for each of the BRICS exchange rates series while EGARCH $(1,1)$ and TGARCH $(1,1)$ models presented the leverage effect. Moreover, the EGARCH $(1,1)$ model illustrated that the asymmetric effects dominate the symmetric effects except for South Africa. The TGARCH $(1,1)$ model on the other hand revealed contrary findings. The paper recommends a study be considered to draw comparison on the different types of GARCH models on the time varying integrated data other than the ones used in the paper.
\end{abstract}

Keywords: ARCH model, GARCH-type models, volatility, interdependence, time series

Subject Classification: C01, C10, C22, C51, C58

\section{Introduction}

The Autoregressive Conditional Heteroskedasticity (ARCH) model has some shortcomings, such as high number of unknown parameters and rapid decay of unconditional autocorrelation function of squared residuals. Bollerslev (1986) in countering the above drawback of ARCH model proposed the Generalized ARCH (GARCH) model, in which conditional variance is also a linear function of its own lags. The GARCH model is also a weighted average of past squared residuals, with diminishing weights that never reach zero. It gives flexible lag structure, and in most cases, it permits more prudent descriptions in most of the situations. The ability of GARCH model to capture volatility has been widely studied in literature (Lama et al., 2016). The Exponential GARCH (EGARCH) due to Nelson (1991) enables the conditional variance to respond to positive and negative residuals asymmetrically. The issue of proper modeling of the long-run dependencies in the conditional mean of macroeconomic and financial time series led to the formulation of the Integrated GARCH (IGARCH) by Bollerslev (1986). IGARCH models possess many of the features of the unit root processes for the mean. According to Teräsvirta (2009), modelling volatility is important in asset returns as volatility is considered a measure of risk, and investors wants a premium for investing in risky assets. The application of the EGARCH process to represent asymmetric responses in the conditional variance to positive and negative errors has motivated to the proposal of the Threshold GARCH or the TGARCH $(p, q)$ process. The TGARCH $(p, q)$ was independently proposed by Zakoian (1994) and Glosten, Jaganathan, and Runkle (1993).

The main objective of this paper is to evaluate the levels of interdependence and dynamic connection among the BRICS financial markets (in particular exchange rates) using appropriate univariate time-series models. The paper examines and reviews the statistical properties of the main time series models considered and determine empirically, and estimate and fit an appropriate ARCH (q) and GARCH (p,q) models to each of the BRICS exchange rates. The paper also estimates the linear dependency among the financial markets (in particular BRICS exchange rates). The 
remainder of the paper is organized as follows. Section 2 presents the literature review. The approach used in the paper is briefly described in Section 3. Section 4 presents the results and discussions. Section 5 gives the conclusion.

\section{Literature Review}

The ARCH model was introduced by Engle (1982) to model volatility. Engle (1982) modeled the heteroskedasticity by relating the conditional variance of the disturbance term to the linear combination of the squared disturbances in the recent past. The ARCH model was transformed to GARCH by Bollerslev (1986). Furthermore, there are other variants of GARCH model. "GARCH models have proven to be able to model conditional volatility and improve the forecasting accuracy of the future volatility of many financial time series" (Goodwin, 2012).

Goyal (2000) examined various GARCH models for stock market data in terms of their ability of delivering volatility forecasts. Using the in sample test on actual volatility the regression produces $R^{2}$ of less than $8 \%$. Overall, the out-of-sample tests revealed that a simpler ARMA model outperformed the GARCH-M model.

Ahmed and Suliman (2011) estimated volatility in the daily returns of the principal stock exchange of Sudan-Khartoum stock exchange (KSE) covering the period of January 2006 to November 2010 using GARCH models. Volatility clustering and leverage effect of index return were captured using both symmetric and asymmetric models. The empirical results revealed that the asymmetric models perform better than the symmetric models and they confirm the presence of leverage effect.

Predescu and Stancu (2011) examined based on the context of current global financial crisis the benefit of selecting an internationally diversified portfolio and the evaluation of the portfolio risk. The portfolio comprised the three benchmarking indexes from Romania, UK and USA. The results showed that international diversification does not reduce risk. Furthermore, ARCH and GARCH models showed that evolution of portfolio volatility is caused by the current global financial crisis. Bala and Asemota (2013) used the GARCH model to examine the exchange rate volatility for Naira/US dollar return and Naira/British pounds and Naira/Euro returns on a monthly series from 1985:1 to 2011:7 and 2004:1 to 2011:7 respectively.

The study by Abdalla (2012) used the GARCH approach to examine exchange rate volatility using daily observations throughout the period of 1 January 2000 to 19 November 2011 in a panel of nineteen Arab countries. In capturing volatility clustering and leverage effect, the study applied both asymmetric and symmetric models. The results of explosive process of volatility were found based on the estimated GARCH $(1,1)$ model. Furthermore, EGARCH $(1,1)$ showed that there is an evidence of leverage effect for majority of currencies. Overall results show that GARCH model can adequately model exchange rate volatility (Abdalla, 2012). Mwita and Nassiuma (2015) used GARCH model in examining the nature and characteristics of Kenyan stock market volatility and its stylized facts. The GARCH $(1,1)$ was shown to be more satisfactory in explaining the volatility of Kenyan stock market and its stylized facts including volatility clustering, fat tails and mean reverting more satisfactory. The overall results depict the evidence of time varying stock return volatility over the sample period. Negative return shocks have a higher volatility than the positive returns shocks.

The paper by Hou and Suardi (2012) modelled and forecasted oil price return volatility using an alternative approach involving nonparametric method using two crude oil markets: Brent and West Texas Intermediate (WTI). The results showed that the volatility forecast of the out-of-sample of the nonparametric GARCH models are superior to that of parametric GARCH models (Hou and Suardi, 2012). The nonparametric GARCH model used in the oil price return volatility to enhance its forecasting accuracy provides the alternative to the parametric GARCH models.

Restrepo and Isabel (2012) estimated both the univariate and multivariate GARCH models in order to examine which provide the better performance in estimating the Value at Risk of the portfolio using daily returns of the portfolio consisting of the five Colombian financial assets. According to the results the univariate GARCH model outperformed the multivariate model in estimating the VaR of the portfolio. Wang and Wu (2012) used univariate and multivariate GARCH-class models in forecasting energy market volatility. Based on the results, it was evident that the univariate GARCH models allowing the asymmetric effects displayed the greater accuracy. Sjöholm (2015) aimed in fitting and comparing the six different classes of heteroskedasticity models in terms of forecasting accuracy of the two different markets: equity and exchange rate. The study forecasted the series to 100 days ahead using MSE as the measurement of error. Based on the results it was evident that there is no much difference between the chosen models. The study showed that the model provides a very good factors in terms of size, momentum, liquidity and volatility factors (Sohn, 2010).

Obeng (2012) evaluated the predictive accuracy of ARCH, GARCH and EGARCH models to assess the predictive accuracy of the models in estimating future values of exchange rate volatility of Canadian dollar, Euro, British pound, 
Swiss franc and Japanese Yen against a base currency in US dollar. The tests were based on both the in-sample and out-of-sample forecasting. Based on the results, the estimated GARCH $(1,1)$ model outperformed all the included models in the in-sample performance. However, in terms of the out-of-sample performance the results were inconclusive. In some cases, the ARCH model performed well, and this can be a credible judgement that simple models should be preferred in specific situations. The study by Guo (2012) employed GARCH model and estimated the volatility using a historic data and EWMA model to the stock data of PetroChna and TCL on the Shanghai and Shenzhen Stock Exchange Market of China. The results were assessed on the mean square error to decide on the best model for calculating assets. The data revealed in both cases that the GARCH model outperformed the EWMA model.

Grek and Mantalos (2014) conducted a study to find the best heteroskedasticity model in terms of best forecasting accuracy of the stocks from the Swedish stock market. Mean Square Error (MSE) was employed as a measure for the performance of the models. Based on the results, it was concluded that the stock market with the higher kurtosis were forecasted better by GARCH model and stocks with the lower kurtosis were forecasted better using EGARCH model. Wei et al. (2010) captured the volatility features of the two crude oil markets: Brent and the WTI using a set of linear and nonlinear GARCH models based on the one, five and twenty day out-of-sample volatility forecast.The performance of the models was evaluated based on the predictive ability test and with more loss function. In general, it is evident that the nonlinear models exhibit a greater forecasting ability than the linear models.

Mokoma and Moroke (2014) used exchange rate, gross domestic product, inflation rate and interest rate in constructing ARCH (1) model, GARCH $(1,1)$ and GARCH $(1,2)$ which were applied in assessing exchange rate volatility in S.A. The study used a time series quarterly data covering the period of 1990: Q1 to 2014: Q2. Based on the results, the GARCH $(1,1)$ model was found to best fit the data and it was used for out-of-sample forecasting. This was also substantiated by the consistencies shown in the exchange rates volatility forecasts.

The majority of the studies above focused on the different stock markets/currencies (eg. Naira/British pound) and the stock exchange using different GARCH models. Some were interested in the exchange rates volatility. Most of the studies reviewed focused on either the asymmetric or symmetric models. The current study examines the performance of GARCH-type models on the BRICS exchange rate volatility. The study employed both the asymmetric and symmetric GARCH-type models on the time varying integrated data.

\section{Materials and Methods}

The data used in this study cover the period ranging from January 2008 to January 2018 and it has 121 observations. The monthly exchange rates of the five BRICS countries were used in the paper. The data used in this study is a national currency of each of the five countries per US Dollar and it was obtained from the Organisation for Economic Cooperation and Development (OECD) website. Data analyses in this study are carried out using R 3.4.4 programming language. The next section presents the models used in the paper.

\subsection{ARCH Model}

An ARCH model, according to Nobel laureate Engle (1982), an ARCH model begin from the point that the regression model is static. The capacity to capture the tendency for volatility in macroeconomic and financial time series is the underlying attribute of the ARCH process. The ARCH models take account of time-varying variance of a single variable time series. The ARCH models exclude the interaction of the variances. In a dynamic linear regression model, the mean equation series $\left(X_{t}: t=1,2, \ldots, N\right)$ takes the form:

$$
X_{t}=Y_{t}^{\prime} \beta+\varepsilon_{t}
$$

where $\varepsilon_{t}=\sigma_{t} w_{t}, \mathrm{w}_{\mathrm{t}} \sim$ iid, $(0,1) . Y_{t}^{\prime}$ is an $m \times 1$ vector of independent variables, which may be lagged values of the dependent variable, $X_{t}$, and $\beta$ is an $m \times 1$ vector of regression parameters. In the basic ARCH process, the square of the disturbance term, $\varepsilon_{t}$, is described as itself following an $\operatorname{AR}(q)$ process:

$$
\begin{gathered}
\varepsilon_{t}^{2}=\lambda_{0}+\sum_{h=1}^{q} \lambda_{h} \varepsilon_{t-h}^{2}+v_{t} \\
\varepsilon_{t}^{2}=\lambda_{0}+\lambda_{1} \varepsilon_{t-1}^{2}+\lambda_{2} \varepsilon_{t-2}^{2}+\cdots+\lambda_{r} \varepsilon_{t-q}^{2}+v_{t}
\end{gathered}
$$

where $v_{t} \sim$ i.i.d. $\left(0, \delta^{2}\right)$. The conditions $\lambda_{0}>0$ and $\lambda_{i} \geq 0$ for $i=1,2, \ldots, q$ ensure that the conditional variance is always positive. In equation (3), the distribution of $\varepsilon_{t}$ conditional $\xi_{t-1}$ is 
where

$$
\varepsilon_{t} \mid \xi_{t-1} \sim N\left(0, \sigma_{t}^{2}\right)
$$

\subsection{GARCH Models}

$$
\xi_{t-1}=X_{t-1}, Y_{t-1}, X_{t-2}, Y_{t-2}, \ldots
$$

A time series $\left(X_{t}: t=1,2, \ldots, N\right)$ follows the Generalised ARCH or $\operatorname{GARCH}(p, q)$ process if it satisfies the mean equation specification:

$$
X_{t}=Y_{t}^{\prime} \beta+\varepsilon_{t}
$$

where $\quad \varepsilon_{t}=\sigma_{t} w_{t}, w_{t} \sim$ i.i.d $(0,1) . Y_{t}^{\prime}$ is an $m \times 1$ vector of independent variables, which may be lagged values of the dependent variable, $X_{t}$, and $\beta$ is an $m \times 1$ vector of regression parameters. The specified conditional variance equation is representable as:

where

$$
\sigma_{t}^{2}=\lambda_{0}+\sum_{i=1}^{q} \lambda_{1} \varepsilon_{t-1}^{2}+\sum_{i=1}^{p} \alpha_{i} \sigma_{i-1}^{2}
$$

$$
\begin{gathered}
\lambda_{0}>0, \\
\lambda_{1} \geq 0 \text { for } i=1,2, \ldots, q, \\
\alpha_{i} \geq 0 \text { for } i=1,2, \ldots, p,
\end{gathered}
$$

and

$$
\varepsilon_{t}=\sigma_{t} w_{t} \text { with } w_{t} \sim \text { i.i.d }(0,1)
$$

The disturbance term is weakly stationary if

$$
\left(\sum_{i=1}^{q} \lambda_{i}+\sum_{i=1}^{p} \alpha_{i}\right)<1
$$

Writing equation (7) as

$$
\sigma_{t}^{2}=\lambda_{0}+\lambda_{1}(B) \varepsilon_{t-1}^{2}+\alpha(B) \sigma_{t}^{2}
$$

where $\lambda(B)=\lambda_{1} B+\lambda_{2} B^{2}+\cdots+\lambda_{q} B^{q}, \alpha(B)=\alpha_{1} B+\alpha_{2} B^{2}+\cdots+\alpha_{p} B^{p}$ and $B$, the backshift operator, equation (9) becomes

$$
\begin{gathered}
\sigma_{t}^{2}-\alpha(B) \sigma_{t}^{2}=\lambda_{0}+\lambda(B) \varepsilon_{t}^{2} \\
{[1-\alpha(B)] \sigma_{t}^{2}=\lambda_{0}+\lambda(B) \varepsilon_{t}^{2}} \\
\sigma_{t}^{2}=\frac{\lambda_{0}}{1-\alpha(B)}+\frac{\lambda(B)}{1-\alpha(B)} \varepsilon_{t}^{2}
\end{gathered}
$$

If the roots $z=\left(z_{1}, z_{2}, \ldots, z_{p}\right)$ of $1-\alpha(B)$ lie outside the unit circle, equation (12) becomes

$$
\begin{gathered}
\sigma_{t}^{2}=\frac{\lambda_{0}}{1-\alpha(1)}+\frac{\lambda(B)}{1-\alpha(B)} \varepsilon_{t}^{2} \\
\sigma_{t}^{2}=\lambda_{0}^{*}+\sum_{i=1}^{\infty} h_{i} \varepsilon_{t-i}^{2}
\end{gathered}
$$

where $\lambda_{0}^{*}=\frac{\lambda_{0}}{1-\alpha(1)}$ and $h_{i}$ is the coefficient of $\beta^{i}$ in the expansion of $\frac{\alpha(B)}{1-\alpha(B)}$. Equation (14) is simply a GARCH $(p, q)$ process with an infinite order ARCH process. Nelson and Cao (1992) have shown the conditions are sufficient to ensure a strictly positive conditional variance, setting

$$
\lambda_{0}^{*}>0 \text { and } h_{i} \geq 0
$$

where $i=1,2,3 \ldots, \infty$ will equally ensure a strictly positive conditional variance. Consider, for instance, the GARCH $(1,2)$ process

$$
\sigma_{t}^{2}=\lambda_{0}+\lambda_{1} \varepsilon_{t-1}^{2}+\alpha \sigma_{t}^{2}
$$

Nelson and Cao (1992) were able to show that the conditional variance is strictly positive if based on the following conditions:

$$
\lambda_{0}>0, \lambda_{1} \geq 0, \alpha_{1} \geq 0, \text { and } \alpha_{1} \lambda_{1}+\lambda_{2} \geq 0,
$$

As in the case of ARCH (1) process, in the most commonly used GARCH $(1,1)$ process, 


$$
\sigma_{t}^{2}=\lambda_{0}+\lambda_{1} \varepsilon_{t-1}^{2}+\alpha_{1} \sigma_{t}^{2}
$$

Hwang and Satchell (1998) have shown in Satchell and Knight (2011) that the logarithmic likelihood function is

$$
\ln \mathrm{L}\left(\lambda_{0}, \lambda_{1}, \alpha_{1}\right)=-\frac{1}{2} \ln (2 \pi)-\frac{1}{2} \sum_{\mathrm{i}=0}^{\mathrm{n}}\left[\ln \left(\sigma_{\mathrm{t}}^{2}\right)+\frac{\mathrm{x}_{\mathrm{t}}^{2}}{\sigma_{\mathrm{t}}^{2}}\right]
$$

Hwang and Satchell (1998) further showed that the s-step-ahead forecast from the GARCH $(1,1)$ process is given by

$$
E\left(X_{t+s}^{2}\right)=\lambda_{0} \sum_{i=0}^{s-1}\left(\lambda_{1}+\alpha_{1}\right)^{i}+\left(\lambda_{1}+\alpha_{1}\right)^{s-1} \lambda_{1} \alpha_{t}^{2}+\left(\lambda_{1}+\alpha_{1}\right)^{s-1} \alpha_{1} X_{t}^{2} \text { for } s>1
$$

and

$$
E\left(X_{t+s}^{2}\right)=\lambda_{0} \sum_{i=0}^{s-1}\left(\lambda_{1}+\alpha_{1}\right)^{i}+\left(\lambda_{1}+\alpha_{1}\right)^{s-1} \sigma_{t+1}^{2} \text { for } s>2
$$

Thus, for large $s$ and $\lambda_{1}+\alpha_{1}<1$, then

$$
E\left(X_{t+s}^{2}\right)=\lambda_{0} \sum_{i=0}^{s-1}\left(\lambda_{1}+\alpha_{1}\right)^{i}=\frac{\lambda_{0}}{1-\lambda_{1}-\alpha_{1}} \text { as } s \rightarrow \infty
$$

Lastly, from the GARCH $(1,1)$ process, the condition

$$
3 \lambda_{1}^{2}+2 \lambda_{1} \alpha_{1}+\alpha_{1}^{2}<1
$$

means the $4^{\text {th }}$ moment (or the kurtosis) of $\varepsilon_{t}$ is greater than that of a normal random variable. Consequently, the GARCH process is capable of producing outliers. One important feature of GARCH (q,p) processes is that the conditional variance of the disturbances of the series $X_{t}$ follows an ARMA (r,q) process. That is if

$$
\varepsilon_{t}^{2}=\sigma_{t}^{2}+u_{t}
$$

then

$$
\varepsilon_{t}^{2}=\lambda_{0}+\sum_{i=1}^{r}\left(\lambda_{1}+\alpha_{i}\right) \varepsilon_{t-1}^{2}+u_{t}-\sum_{i=1}^{p} \alpha_{i}\left(\varepsilon_{t-1}^{2}-\sigma_{i-1}^{2}\right)
$$

equation (25) can be written as

$$
\varepsilon_{t}^{2}=\lambda_{0}+\sum_{i=1}^{r}\left(\lambda_{1}+\alpha_{i}\right) \varepsilon_{t-1}^{2}+u_{t}-\sum_{i=1}^{q} \alpha_{i} u_{t-1}
$$

where $r=\max (q, p), \lambda_{i}=0$ for $i>p, \alpha_{i}=0$ for $i>q$. It comes from equation (26) that $\varepsilon_{t}^{2}$ has an ARMA $(\mathrm{r}, \mathrm{q})$ representation. Therefore, it is expected that the residuals from the fitted ARMA process follow a white noise process. The autocorrelation function of the squared residuals, $\hat{\varepsilon}_{t}^{2}$, aid in determining the order of the GARCH process. In fact, McLeod and Li (1983) suggest estimating the best-fitting ARIMA model (or regression model) and calculating the sample autocorrelation (ACF) of the squared residuals, $\varepsilon_{t}^{2}$ :

$$
\hat{\rho}_{k}(\varepsilon)=\frac{\sum_{t=k+1}^{N}\left(\hat{\varepsilon}_{t}^{2}-\widehat{\sigma}^{2}\right)\left(\hat{\varepsilon}_{t-k}^{2}-\widehat{\sigma}^{2}\right)}{\sum_{t=1}^{N}\left(\hat{\varepsilon}_{t}^{2}-\widehat{\sigma}^{2}\right)}
$$

where

$$
\hat{\sigma}^{2}=\sum_{t=1}^{N} \frac{\hat{\varepsilon}_{t}^{2}}{N}
$$

The Box-Pierce Portmanteau statistic

$$
\varrho(\varepsilon)=N(N+2) \sum_{k=1}^{m} \frac{\widehat{\gamma}_{k(\varepsilon)}}{(N-K)}
$$

which is asymptotically distributed as $\chi^{2}(m)$, where $m$ is the number of autocorrelations used in the test, can then be used to test for groups of significant coefficients. Rejecting the null hypothesis, $H_{0}: \hat{\varepsilon}_{t}^{2}$ are uncorrelated, is equivalent to rejecting the null hypothesis of no ARCH or GARCH errors. With no specific alternative to the test, Engle (1982) recommends a Lagrangian Multiplier (LM) test of the alternative hypothesis of ARCH $(q)$ disturbances since such a test can be computed from running the auxiliary regression. Researchers have revealed that a process greater than $\operatorname{GARCH}(1,2)$ or $\operatorname{GARCH}(2,1)$ are very uncommon. 


\subsection{Exponential GARCH (EGARCH) Process}

A possible limitation of the GARCH process is that the conditional variance $\sigma_{t}^{2}$ responds to positive and negative residuals $\varepsilon_{t-i}$ in the same manner, i.e. $\sigma_{t}^{2}$ may be symmetric in $\varepsilon_{t-i}$. Nelson (1991) argued that a symmetric conditional variance function may be inappropriate for modelling volatility of returns on stocks since it cannot represent the leverage effect which is a negative correlation between volatility and past returns. Nelson (1991) therefore proposed a concept of Exponential GARCH or EGARCH. The EGARCH process enables the conditional variance to respond to positive and negative residuals asymmetrically. A time series $\left(X_{t}: t=1,2, \ldots, N\right)$ follows an $\operatorname{EGARCH}(p, q)$ process if it satisfies the following specifications:

$$
\begin{gathered}
\mathrm{X}_{\mathrm{t}}=\mathrm{Y}_{\mathrm{t}}^{\prime} \beta+\varepsilon_{\mathrm{t}} \text { with } \varepsilon_{\mathrm{t}}=\sigma_{\mathrm{t}} \mathrm{W}_{\mathrm{t}} \text { where } \mathrm{w}_{\mathrm{t}} \sim \mathrm{N}(0,1) \\
\ln \left(\sigma_{t}^{2}\right)=\omega+\beta \ln \left(\sigma_{t-1}^{2}\right)+\gamma \frac{\varepsilon_{t-1}}{\sqrt{\sigma_{t-1}^{2}}}+\alpha\left[\frac{\left|\varepsilon_{t-1}\right|}{\sqrt{\sigma_{t-1}^{2}}}-\sqrt{\frac{2}{\pi}}\right]
\end{gathered}
$$

where $\omega$ is a constant parameter, $\beta \ln \left(\sigma_{t-1}^{2}\right)$ denotes the fitted variance from the previous period, $\gamma$ is the value of the leverage term, $\alpha$ is the symmetric effect and $\beta$ denotes the past volatility coefficient. If the value of $\gamma>0$ then it is concluded that there is a larger impact for negative shocks on the conditional variance.

\subsection{Threshold GARCH (TGARCH) Process}

The application of the EGARCH process to represent asymmetric responses in the conditional variance to positive and negative errors has motivated to the proposal of the Threshold GARCH or the TGARCH (p,q) process. Proposed independently by Zakoian (1994) and Glosten et al. (1993), the specification for the conditional variance is:

$$
\sigma_{t}^{2}=\lambda_{0}+\sum_{i=q}^{q} \lambda_{i} \varepsilon_{i-1}^{2}+c_{1} \varepsilon_{t-1}^{2} d_{t-1}+\sum_{i=1}^{p} \alpha_{i} \sigma_{t-1}^{2}
$$

where

$$
d_{t}=\left\{\begin{array}{lll}
1 & , \quad \varepsilon_{t}>0 \\
0 \quad & \varepsilon_{t} \leq 0 .
\end{array}\right.
$$

In this specification, news has differential impacts on the conditional variance, $\sigma_{t}^{2}$. Consider the simple TGARCH $(1,1)$ process

where

$$
\sigma_{t}^{2}=\lambda_{0}+\lambda_{1} \varepsilon_{t-1}^{2}+c_{1} \varepsilon_{t-1}^{2} d_{t-1}+\alpha_{1} \sigma_{t-1}^{2}
$$

$$
d_{t}=\left\{\begin{array}{lll}
1, & \varepsilon_{t}>0 \\
0 \quad, & \varepsilon_{t} \leq 0 .
\end{array}\right.
$$

For good news, $\varepsilon_{t} \leq 0$ and so $d_{t}=0$. Hence, equation (33) becomes

$$
\sigma_{t}^{2}=\lambda_{0}+\lambda_{1} \varepsilon_{t-1}^{2}+\alpha_{1} \sigma_{t-1}^{2}
$$

Similarly, for bad news, $\varepsilon_{t}>0$ and so $d_{t}=1$. The specification of equation (33) is

$$
\sigma_{t}^{2}=\lambda_{0}+\left(\lambda_{1}+c\right) \varepsilon_{t-1}^{2}+\alpha_{1} \sigma_{t-1}^{2}
$$

Equation (34) and (35) show that the impact of good news is $\lambda_{1}$, while bad news has an impact of $\lambda_{1}+c$. Leverage effects exist if $c_{1}>0$. News impact is asymmetric if $c_{1} \neq 0$.

\section{Results}

This section of the paper presents the data analysis and interpretation of results. 


\subsection{The Results for ARCH Model}

This section presents the results for ARCH model. The results are summarised in the following Table 1.

Table 1. Parameter estimation

\begin{tabular}{llllll}
\hline $\begin{array}{l}\text { Exchange } \\
\text { Rates }\end{array}$ & Parameter & Estimate & Std. Error & t-value & p-value \\
\hline Brazil & $\mathrm{Mu}$ & 0.001 & 0.0001 & 7.098 & $0.000 * * *$ \\
\cline { 2 - 5 } & $\mathrm{ar} 1$ & 0.411 & 0.147 & 2.806 & $0.005 * *$ \\
\hline China & $\mathrm{Mu}$ & 0.00003 & 0.000002 & 17.362 & $<.00002 * * *$ \\
\cline { 2 - 5 } & $\mathrm{ar} 1$ & 0.504 & 0.181 & 2.784 & $0.005 * *$ \\
\hline India & $\mathrm{Mu}$ & 0.0003 & 0.00003 & 8.128 & $<0.0001 * * *$ \\
\cline { 2 - 5 } & $\mathrm{ar} 1$ & 0.435 & 1.978 & 2.201 & 0.278 \\
\hline Russia & $\mathrm{Mu}$ & 0.001 & 0.0001 & 5.434 & $<0.0001 * * *$ \\
\cline { 2 - 5 } & $\mathrm{ar} 1$ & 0.852 & 0.247 & 3.447 & $0.001 * * *$ \\
\hline South Africa & $\mathrm{Mu}$ & 0.001 & 0.0002 & 3.907 & $0.0001 * * *$ \\
\cline { 2 - 5 } & $\mathrm{ar} 1$ & 0.765 & 0.143 & 5.360 & $<0.0001 * * *$ \\
\hline
\end{tabular}

Note: '***’, ‘**', ‘*’ and '.' indicates significant codes at $0.001,0.01,0.05$ and 0.1 respectively

The ARCH (1) effect is significant with probability values below all the levels of significance except for India. Since the ARCH (1) model is significant according to the results, this is an indication that this mean equation could be fit to the GARCH variance equation.

\subsection{The Results for GARCH Model}

This section presents the univariate GARCH $(1,1)$, EGARCH $(1,1)$ and TGARCH $(1,1)$ models for the BRICS exchange rates. As seen in the previous section on ARCH, all the BRICS exchange rates showed some presence of ARCH errors. Depending of the nature of the time series, the models may present different assumptions of conditional distribution. The Gaussian normal distribution appeared to be the most common conditional distribution. There are two conditional distributions namely: Student's t distribution $(s t d)$ and Skewed Student's t (sstd). Table 2 below shows the fitted std and sstd on GARCH $(1,1), \operatorname{EGARCH}(1,1)$ and TGARCH $(1,1)$.

Table 2. The AIC values under std and sstd conditional distributions for each of the BRICS exchange rates

\begin{tabular}{lllllll}
\hline \multirow{2}{*}{ Exchange Rates } & \multicolumn{7}{c}{ AIC } \\
\cline { 2 - 7 } & \multicolumn{2}{c}{ GARCH $(\mathbf{1 , 1})$} & \multicolumn{1}{c}{ EGARCH (1,1) } & \multicolumn{2}{c}{ TGARCH (1,1) } \\
\cline { 2 - 7 } & Std & sstd & std & sstd & std & sstd \\
\hline BRAZIL & -3.786 & -3.831 & -3.857 & -3.820 & -3.785 & -3.901 \\
\hline CHINA & -7.947 & -7.931 & -7.998 & -8.072 & -7.872 & -- \\
\hline INDIA & -5.035 & -5.028 & -5.046 & -5.030 & -5.045 & -5.036 \\
\hline RUSSIA & -3.682 & -3.668 & -3.682 & -3.667 & -3.674 & -3.536 \\
\hline SOUTH AFRICA & -3.775 & -3.789 & -3.777 & -3.762 & -3.788 & -3.784 \\
\hline
\end{tabular}

Table 2 indicated that std has the most lowest AIC values of all the BRICS exchange rates in all the three models. Therefore GARCH $(1,1)$, EGARCH $(1,1)$ and TGARCH $(1,1)$ models were fitted using the std. The results are presented in the Table 3 below. 
Table 3. Model parameter estimates for each of the BRICS exchange rates

\begin{tabular}{|c|c|c|c|c|}
\hline Exchange Rates & Parameter & GARCH $(1,1)$ & EGARCH $(\mathbf{1 , 1})$ & TGARCH $(\mathbf{1 , 1})$ \\
\hline \multirow[t]{10}{*}{ Brazil } & \multirow[t]{2}{*}{$\mu$} & -0.001 & & 0.001 \\
\hline & & $(0.748)$ & & $(0.000 * * *)$ \\
\hline & \multirow[t]{2}{*}{$\omega$} & 0.001 & -5.871 & 0.0001 \\
\hline & & $(0.000 * * *)$ & $(0.001 * * *)$ & $(0.000 * * *)$ \\
\hline & \multirow[t]{2}{*}{$\alpha_{1}$} & 0.455 & 0.346 & 0.078 \\
\hline & & $\left(0.044^{*}\right)$ & $(0.032 *)$ & $(0.000 * * *)$ \\
\hline & \multirow[t]{2}{*}{$\beta_{1}$} & 0.014 & 0.136 & 0.935 \\
\hline & & $(0.894)$ & $(0.589)$ & $(0.000 * * *)$ \\
\hline & \multirow[t]{2}{*}{$\gamma_{1}$} & & 0.673 & 0.297 \\
\hline & & & $(0.003 * *)$ & $(0.000 * * *)$ \\
\hline \multirow[t]{10}{*}{ China } & \multirow[t]{2}{*}{$\mu$} & -0.001 & & -0.001 \\
\hline & & $(0.040 *)$ & & $(0.000 * * *)$ \\
\hline & \multirow[t]{2}{*}{$\omega$} & 0.000001 & -0.249 & 0.000 \\
\hline & & $(0.761)$ & $(0.275)$ & $(0.909)$ \\
\hline & \multirow[t]{2}{*}{$\alpha_{1}$} & 0.408 & -0.373 & 0.060 \\
\hline & & $(0.002 * *)$ & $\left(0.015^{*}\right)$ & $(0.000 * * *)$ \\
\hline & \multirow[t]{2}{*}{$\beta_{1}$} & 0.591 & 0.985 & 0.997 \\
\hline & & $(0.000 * * *)$ & $(0.000 * * *)$ & $(0.000 * * *)$ \\
\hline & \multirow[t]{2}{*}{$\gamma_{1}$} & & 1.001 & -0.124 \\
\hline & & & $(0.004 * *)$ & $(0.000 * * *)$ \\
\hline \multirow[t]{10}{*}{ India } & \multirow[t]{2}{*}{$\mu$} & 0.001 & & 0.002 \\
\hline & & $(0.373)$ & & $(0.231)$ \\
\hline & \multirow[t]{2}{*}{$\omega$} & 0.00003 & -0.889 & 0.00003 \\
\hline & & $(0.403)$ & $(0.192)$ & $(0.263)$ \\
\hline & \multirow[t]{2}{*}{$\alpha_{1}$} & 0.201 & 0.168 & 0.248 \\
\hline & & $(0.132)$ & $(0.097 \cdot)$ & $(0.094)$ \\
\hline & \multirow[t]{2}{*}{$\beta_{1}$} & 0.753 & 0.892 & 0.777 \\
\hline & & $(0.000 * * *)$ & $(0.000 * * *)$ & $(0.000 * * *)$ \\
\hline & \multirow[t]{2}{*}{$\gamma_{1}$} & & 0.279 & -0.255 \\
\hline & & & $(0.120)$ & $(0.115)$ \\
\hline \multirow[t]{8}{*}{ Russia } & \multirow[t]{2}{*}{$\mu$} & -0.002 & & -0.001 \\
\hline & & $(0.523)$ & & $(0.825)$ \\
\hline & \multirow[t]{2}{*}{$\omega$} & 0.0003 & -1.880 & 0.0003 \\
\hline & & $(0.011 * *)$ & $\left(0.017^{*}\right)$ & $(0.009 * *)$ \\
\hline & \multirow[t]{2}{*}{$\alpha_{1}$} & 0.713 & 0.158 & 0.853 \\
\hline & & $(0.002 * *)$ & $(0.210)$ & $\left(0.006^{* *}\right)$ \\
\hline & \multirow[t]{2}{*}{$\beta_{1}$} & 0.240 & 0.717 & 0.254 \\
\hline & & $\left(0.055^{*}\right)$ & $(0.000 * * *)$ & $(0.044 *)$ \\
\hline
\end{tabular}




\begin{tabular}{|c|c|c|c|c|}
\hline Exchange Rates & Parameter & GARCH $(1,1)$ & EGARCH $(1,1)$ & TGARCH $(1,1)$ \\
\hline & \multirow[t]{2}{*}{$\gamma_{1}$} & & 0.957 & -0.394 \\
\hline & & & $\left(0.000^{* * *}\right)$ & $(0.288)$ \\
\hline \multirow[t]{10}{*}{ South Africa } & \multirow[t]{2}{*}{$\mu$} & 0.005 & & 0.004 \\
\hline & & $(0.122)$ & & $(0.072)$ \\
\hline & \multirow[t]{2}{*}{$\omega$} & 0.0003 & -0.838 & 0.000003 \\
\hline & & $(0.475)$ & (0.186) & $(0.642)$ \\
\hline & \multirow[t]{2}{*}{$\alpha_{1}$} & 0.150 & 0.148 & 0.039 \\
\hline & & $(0.400)$ & $(0.122)$ & $(0.000 * * *)$ \\
\hline & \multirow[t]{2}{*}{$\beta_{1}$} & 0.653 & 0.879 & 1.000 \\
\hline & & $(0.087 \cdot)$ & $\left(0.000^{* * *}\right)$ & $(0.000 * * *)$ \\
\hline & \multirow[t]{2}{*}{$\gamma_{1}$} & & 0.126 & -0.102 \\
\hline & & & $(0.407)$ & $(0.000 * * *)$ \\
\hline
\end{tabular}

Note: '***', '**', '*' and ' ' indicates significant codes at $0.001,0.01,0.05$ and 0.1 respectively. The p-value is in parentheses.

The following models are deduced from the above Table 3, the GARCH $(1,1)$ model equations for each BRICS exchange rates are written as follows:

$$
\begin{gathered}
x_{r}(\text { Brazil })=-0.001( \pm 0.003)+\varepsilon_{t} \\
\sigma_{t}^{2}=0.001( \pm 0.0002)+0.455( \pm 0.226) \sigma_{t-1}^{2}+0.014( \pm 0.103) \sigma_{t-1}^{2} \\
x_{r}(\text { China })=-0.001( \pm 0.0003)+\varepsilon_{t} \\
\sigma_{t}^{2}=0.000001( \pm 0.000003)+0.408( \pm 0.134) \sigma_{t-1}^{2}+0.591( \pm 0.095) \sigma_{t-1}^{2} \\
x_{r}(\text { India })=0.001( \pm 0.001)+\varepsilon_{t}, \\
\sigma_{t}^{2}=0.00003( \pm 0.00003)+0.201( \pm 0.133) \sigma_{t-1}^{2}+0.753( \pm 0.143) \sigma_{t-1}^{2} \\
x_{r}(\text { Russia })=-0.002( \pm 0.003)+\varepsilon_{t}, \\
\sigma_{t}^{2}=0.0003( \pm 0.0001)+0.713( \pm 0.225) \sigma_{t-1}^{2}+0.240( \pm 0.125) \sigma_{t-1}^{2} \\
x_{r}(\text { SouthAfrica })=0.005( \pm 0.003)+\varepsilon_{t}, \\
\sigma_{t}^{2}=0.0003( \pm 0.0004)+0.150( \pm 0.178) \sigma_{t-1}^{2}+0.653( \pm 0.382) \sigma_{t-1}^{2}
\end{gathered}
$$

$x_{r}$ represents the exchange rates for each of the BRICS countries whereas $\sigma_{t}^{2}$ symbolises the volatility part of the GARCH $(1,1)$ model equation for each BRICS exchange rates. The sum of the estimates $\hat{\alpha}_{1}$ and $\hat{\beta}_{1}$ of all the BRICS exchange rates series are less than one meaning that the unconditional volatility for each of the BRICS exchange rates series is finite. The results further revealed that China has the highest volatility persistence value of $\hat{\alpha}_{1}+\hat{\beta}_{1}=0.999$, followed by India with the value of $\hat{\alpha}_{1}+\hat{\beta}_{1}=0.954$, followed by Russia with the value of $\hat{\alpha}_{1}+$ $\hat{\beta}_{1}=0.943$, followed by South Africa with the value of $\hat{\alpha}_{1}+\hat{\beta}_{1}=0.803$ and the least is Brazil with volatility persistence value of $\hat{\alpha}_{1}+\hat{\beta}_{1}=0.469$.

Table 3 further shows the leverage effects, $\gamma_{1}$, of all the BRICS countries exchange rates is greater than zero or positive coefficients implying that an increase in the BRICS exchange rate have greater impact on the conditional volatility as compare to the decrease in the BRICS exchange rate. The impact for South Africa is very weak $\gamma$ (0.126) and smaller than the symmetric effect $\alpha(0.148)$. The impact for the rest of the BRICS countries (Brazil $\gamma$ (0.673); China $\gamma$ (1.001); India $\gamma(0.279)$; Russia $\gamma$ (0.957)) appears to be very strong and larger than the 
symmetric effect of those BRICS countries (Brazil $\alpha$ (0.346); China $\alpha$ (-0.373); India $\alpha$ (0.168); Russia $\alpha$ $(0.158))$. The relative size of the two groups of coefficients $(\gamma$ and $\alpha)$ suggests that the asymmetric effects dominates the symmetric effects except for South Africa which illustrated the opposite. All the BRICS countries stationarity is also assured by the past volatility coefficient $\beta$ less than one. It must be noted, however, that $\beta$ for China, India, Russia and South Africa implies that there is the presence of high shock persistence in the exchange rates. Brazil on one hand has low shock persistence in their exchange rates. The following models are deduced from the above Table 3, the EGARCH $(1,1)$ conditional variance equations for each BRICS exchange rates are written as follows:

Brazil

$$
\ln \left(\sigma_{t}^{2}\right)=-5.871+0.136 \ln \left(\sigma_{t-1}^{2}\right)+0.673 z_{t-1}+0.346\left(\left|z_{t-1}\right|+\sqrt{2 / \pi}\right)
$$

China

$$
\ln \left(\sigma_{t}^{2}\right)=-0.249+0.985 \ln \left(\sigma_{t-1}^{2}\right)+1.001 z_{t-1}-0.373\left(\left|z_{t-1}\right|+\sqrt{2 / \pi}\right)
$$

India

$$
\ln \left(\sigma_{t}^{2}\right)=-0.889+0.892 \ln \left(\sigma_{t-1}^{2}\right)+0.279 z_{t-1}+0.168\left(\left|z_{t-1}\right|+\sqrt{2 / \pi}\right)
$$

Russia

$$
\ln \left(\sigma_{t}^{2}\right)=-1.880+0.717 \ln \left(\sigma_{t-1}^{2}\right)+0.957 z_{t-1}+0.158\left(\left|z_{t-1}\right|+\sqrt{2 / \pi}\right)
$$

South Africa

$$
\ln \left(\sigma_{t}^{2}\right)=-0.838+0.879 \ln \left(\sigma_{t-1}^{2}\right)+0.126 z_{t-1}+0.148\left(\left|z_{t-1}\right|+\sqrt{2 / \pi}\right)
$$

where

$$
z_{t}=\frac{\varepsilon_{t}}{\sqrt{\sigma_{t}^{2}}}
$$

The sum of the estimates $\hat{\alpha}_{1}$ and $\hat{\beta}_{1}$ of all the BRICS exchange rates series are less than one except for India and South Africa which are slightly greater than one. This means that the unconditional volatility for the three BRICS exchange rates series is finite. The results further revealed that India has the highest volatility persistence value of $\hat{\alpha}_{1}+\hat{\beta}_{1}=1.060$, followed by South Africa with the value of $\hat{\alpha}_{1}+\hat{\beta}_{1}=1.027$, followed by Russia with the value of $\hat{\alpha}_{1}+\hat{\beta}_{1}=0.875$, followed by China with the value of $\hat{\alpha}_{1}+\hat{\beta}_{1}=0.612$ and the least is Brazil with volatility persistence value of $\hat{\alpha}_{1}+\hat{\beta}_{1}=0.482$.

Table 3 shows the leverage effects, $\gamma_{1}$, of all the BRICS countries exchange rates is less than zero or negative coefficients, implying that an decrease in the BRICS exchange rate have lesser impact on the conditional volatility as compared to the increase in the BRICS exchange rate except for Brazil. The impact for Brazil is strong $\gamma(0.297)$ and larger than the symmetric effect $\alpha$ (0.078). The impact for the rest of the BRICS countries (China $\gamma$ (-0.124); India $\gamma$ (-0.255); Russia $\gamma$ (-0.394); South Africa $\gamma(-0.102))$ appears to be very weak $\gamma(0.126)$ and smaller than the symmetric effect of those BRICS countries (China $\alpha$ (0.060); India $\alpha$ (0.248); Russia $\alpha$ (0.853); South Africa $\alpha(0.039)$ ). The estimated $\gamma$ for Brazil proves that the bad news has larger effect to the volatility as compared to the remaining BRICS exchange rates. The relative size of the two groups of coefficients $(\gamma$ and $\alpha)$ suggests that the symmetric effects dominate the asymmetric effects except for Brazil which illustrated the opposite. All the BRICS countries stationarity is also assured by the past volatility coefficient $\beta$ less than one except for 
South Africa. It must be noted, however, that $\beta$ for Brazil, China, India and South Africa implies that there is the presence of high shock persistence in the exchange rates. Russia on one hand has low shock persistence in their exchange rates.

The following models are deduced from the above Table 3, the TGARCH $(1,1)$ model equations for each BRICS exchange rates are written as follows:

$$
\begin{gathered}
x_{r}(\text { Brazil })=0.001( \pm 0.000045)+\varepsilon_{t}, \\
\sigma_{t}^{2}=0.0001+0.078 \epsilon_{t-1}^{2}+0.935 \epsilon_{t-1}^{2}+0.297 \epsilon_{t-1}^{2}\left(\epsilon_{t-1}^{2}>0\right) \\
x_{r}(\text { China })=-0.001( \pm 0.0003)+\varepsilon_{t} \\
\sigma_{t}^{2}=0.000+0.060 \epsilon_{t-1}^{2}+0.997 \epsilon_{t-1}^{2}-0.124 \epsilon_{t-1}^{2}\left(\epsilon_{t-1}^{2}>0\right) \\
x_{r}(\text { India })=0.002( \pm 0.001)+\varepsilon_{t} \\
\sigma_{t}^{2}=0.00003+0.248 \epsilon_{t-1}^{2}+0.777 \epsilon_{t-1}^{2}-0.255 \epsilon_{t-1}^{2}\left(\epsilon_{t-1}^{2}>0\right) \\
x_{r}(\text { Russia })=-0.0006( \pm 0.003)+\varepsilon_{t} \\
\sigma_{t}^{2}=0.0003+0.853 \epsilon_{t-1}^{2}+0.254 \epsilon_{t-1}^{2}-0.394 \epsilon_{t-1}^{2}\left(\epsilon_{t-1}^{2}>0\right) \\
x_{r}(\text { SouthAfrica })=0.005( \pm 0.002)+\varepsilon_{t}, \\
\sigma_{t}^{2}=0.000003+0.039 \epsilon_{t-1}^{2}+1.000 \epsilon_{t-1}^{2}-0.102 \epsilon_{t-1}^{2}\left(\epsilon_{t-1}^{2}>0\right)
\end{gathered}
$$

The sum of the estimates $\hat{\alpha}_{1}$ and $\hat{\beta}_{1}$ of all the BRICS exchange rates series are all slightly greater than one. This means that the unconditional volatility for all the BRICS exchange rates is finite. The results further revealed that Russia has the highest volatility persistence value of $\hat{\alpha}_{1}+\hat{\beta}_{1}=1.107$, followed by China with the value of $\hat{\alpha}_{1}+$ $\hat{\beta}_{1}=1.057$, followed by South Africa with the value of $\hat{\alpha}_{1}+\hat{\beta}_{1}=1.039$, followed by India with the value of $\hat{\alpha}_{1}+$ $\hat{\beta}_{1}=1.025$ and the least is Brazil with volatility persistence value of $\hat{\alpha}_{1}+\hat{\beta}_{1}=1.013$.

The next section 4.3 illustrates the diagnostic tests.

\subsection{Diagnostic Tests}

Model adequacy testing is done using the following diagnostic tests: Goodness of fit test; Ljung-Box (R), Ljung-Box $\left(\mathrm{R}^{2}\right)$, and ARCH-LM.

Table 4. Diagnostic test of the GARCH $(1,1)$, EGARCH $(1,1)$ and TGARCH $(1,1)$ model

\begin{tabular}{lllll}
\hline Exchange Rates & Diagnostic test & GARCH (1,1) & EGARCH (1,1) & TGARCH (1,1) \\
\hline Brazil & Goodness of fit test & 15.670 & 17.670 & 23.670 \\
& & $(0.679)$ & $(0.545)$ & $(0.209)$ \\
\cline { 2 - 5 } & Ljung-Box $(\mathrm{R})$ & 17.090 & 15.060 & 18.690 \\
& $\left(3.567 \mathrm{e}-05^{* * *}\right)$ & $(1.042 \mathrm{e}-04 * * *)$ & $\left(1.538 \mathrm{e}-05^{* * *}\right)$ \\
\cline { 2 - 5 } & Ljung-Box $\left(\mathrm{R}^{2}\right)$ & 2.377 & 0.070 & 8.068 \\
& $(0.1232)$ & $(0.791)$ & $\left(0.005^{* *}\right)$ \\
\cline { 2 - 5 } & ARCH-LM & 0.3834 & 0.1115 & 0.792 \\
& & $(0.5358)$ & $(0.739)$ & $(0.374)$ \\
\hline China & Goodness of fit test & 19.330 & 33.670 & 34.000 \\
& & $(0.456)$ & $(0.201)$ & $\left(0.018^{* *}\right)$ \\
\cline { 2 - 5 } & Ljung-Box $(\mathrm{R})$ & 3.365 & 0.786 & 15.690 \\
& & $(0.067 \cdot)$ & $(0.375)$ & $\left(7.470 \mathrm{e}-05^{* * *}\right)$ \\
\cline { 2 - 4 } & Ljung-Box $\left(\mathrm{R}^{2}\right)$ & 0.030 & 0.048 & 0.004 \\
& & $(0.863)$ & $(0.827)$ & $(0.950)$ \\
\hline
\end{tabular}




\begin{tabular}{|c|c|c|c|c|}
\hline Exchange Rates & Diagnostic test & GARCH $(\mathbf{1 , 1})$ & EGARCH $(1,1)$ & TGARCH $(1,1)$ \\
\hline & ARCH-LM & 0.027 & 0.039 & 0.06435 \\
\hline & & $(0.870)$ & $(0.843)$ & $(0.800)$ \\
\hline \multirow[t]{8}{*}{ India } & Goodness of fit test & 8.667 & 17.330 & 13.000 \\
\hline & & $(0.979)$ & $(0.567)$ & $(0.839)$ \\
\hline & Ljung-Box (R) & 7.111 & 5.572 & 6.144 \\
\hline & & $\left(0.008^{* *}\right)$ & $(0.018 * *)$ & $(0.013 * *)$ \\
\hline & Ljung-Box $\left(\mathrm{R}^{2}\right)$ & 0.142 & 0.250 & 0.218 \\
\hline & & $(0.706)$ & $(0.617)$ & $(0.641)$ \\
\hline & ARCH-LM & 1.884 & 2.286 & 2.607 \\
\hline & & $(0.170)$ & $(0.131)$ & $(0.106)$ \\
\hline \multirow[t]{8}{*}{ Russia } & Goodness of fit test & 20.670 & 16.000 & 13.000 \\
\hline & & $(0.356)$ & $(0.657)$ & $(0.839)$ \\
\hline & Ljung-Box (R) & 11.260 & 10.770 & 9.356 \\
\hline & & $(0.001 * * *)$ & $(0.001)$ & $(0.002 * *)$ \\
\hline & Ljung-Box $\left(\mathrm{R}^{2}\right)$ & 0.044 & 0.005 & 0.265 \\
\hline & & $(0.834)$ & $(0.943)$ & $(0.607)$ \\
\hline & ARCH-LM & 0.928 & 0.974 & 0.913 \\
\hline & & $(0.335)$ & $(0.324)$ & $(0.339)$ \\
\hline \multirow[t]{8}{*}{ South Africa } & Goodness of fit test & 23.670 & 28.000 & 13.670 \\
\hline & & $(0.209)$ & $(0.083)$ & $(0.803)$ \\
\hline & Ljung-Box (R) & 5.650 & 6.721 & 9.105 \\
\hline & & $(0.017 *)$ & $\left(0.010^{* *}\right)$ & $(0.003 * *)$ \\
\hline & Ljung-Box $\left(\mathrm{R}^{2}\right)$ & 0.108 & 0.549 & 0.906 \\
\hline & & $(0.743)$ & $(0.459)$ & $(0.341)$ \\
\hline & ARCH-LM & 0.150 & 0.410 & 0.389 \\
\hline & & $(0.698)$ & $(0.522)$ & $(0.533)$ \\
\hline
\end{tabular}

Note: '***', '**', '*' and ',' indicates significant codes at $0.001,0.01,0.05$ and 0.1 respectively. The p-value is in parentheses.

The data in the above Table 4 shows that all the BRICS exchange rates have no ARCH errors, since all the p-values of the ARCH-LM test are greater than 0.05 level of significance. The Ljung-Box $\left(\mathrm{R}^{2}\right)$ revealed that the residuals of the squared BRICS exchange rates do not have serial correlation. All the BRICS exchange rates show that the fitted residuals are normally distributed except for Russia which has a p-value less than 0.05 in both GARCH $(1,1)$ and TGARCH $(1,1)$ models. Therefore, GARCH $(1,1)$, EGARCH $(1,1)$ and TGARCH $(1,1)$ under the std conditional distribution appears to be adequate and can be used for further analysis.

\section{Conclusion}

The paper modeled the BRICS exchange rates using the three univariate models viz GARCH $(1,1)$, EGARCH $(1,1)$ and TGARCH $(1,1)$. Monthly time series data of the BRICS exchange rates starting from January 2008 to January 2018 were used and this covers the scope before the inception of BRICS. The findings of this study may not be generalised as they only apply to the data used in the study. The findings may not be transferable to other time frames. The ARCH and GARCH model parameters were estimated and presented. The ARCH (1) model is statistically significant according to the results implying that the mean equation could be fit to the GARCH variance 
equation. Univariate GARCH $(1,1)$, EGARCH $(1,1)$ and TGARCH $(1,1)$ models for the BRICS exchange rates were fitted to the data. The results of the GARCH $(1,1)$ are in line with the views by Mokoma and Moroke (2014).

The diagnostic results revealed that GARCH $(1,1)$, EGARCH $(1,1)$ and TGARCH $(1,1)$ under the std conditional distribution appears to be adequate. The views were supported by Teräsvirta (2009) and Goyal (2000). The results were also supported by the study by Minović (2017). The EGARCH $(1,1)$ results are in line with Grek and Mantalos (2014) and supported by Abdalla (2012). The estimated $\gamma$ for all the BRICS exchange rates proves that the bad news has no effect to the volatility on the TGARCH $(1,1)$ model. The relative size of the two groups of coefficients $(\gamma$ and $\alpha$ ) suggests that the symmetric effects dominates the asymmetric effects except for Brazil which illustrated the opposite. The results are in line with Grek and Mantalos (2014) and supported by Ahmed and Suliman (2011).

Based on the findings, the paper recommends a study be considered to draw comparison on the different types of GARCH models on the time varying integrated data other than the ones used in the paper. This may enlighten the discussion on the up and coming scholars on which GARCH model is more reliable for the time varying integrated data. This will determine which of the GARCH model perform the best of all the models. Policies governing the exchange rates and how they can be managed are recommended to assist trade amongst the BRICS countries.

\section{References}

Abdalla, S. Z. S. (2012). Modelling exchange rate volatility using GARCH models: Empirical evidence from Arab countries. International Journal of Economics and Finance, 4, 216. https://doi.org/10.5539/ijef.v4n3p216

Ahmed, A. E. M., \& Suliman, S. Z. (2011). Modeling stock market volatility using GARCH models evidence from Sudan. International Journal of Business and Social Science, 2.

Bala, D. A., \& Asemota, J. O. (2013). Exchange-rates volatility in Nigeria: application of garch models with exogenous break. CBN Journal of Applied Statistics, 4, 89-116.

Bollerslev, T. (1986). Generalized autoregressive conditional heteroskedasticity. Journal of econometrics, 31, 307-327. https://doi.org/10.1016/0304-4076(86)90063-1.

Engle, R. F. (1982). Autoregressive conditional heteroscedasticity with estimates of the variance of United Kingdom inflation. Econometrica: Journal of the Econometric Society, 987-1007. https://doi.org/10.2307/1912773

Glosten, L. R., Jagannathan, R., \& Runkle, D. E. (1993). On the relation between the expected value and the volatility of the nominal excess return on stocks. The journal of finance, 48, 1779-1801. https://doi.org/10.1111/j.1540-6261.1993.tb05128.x

Goodwin, D. (2012). Modeling and Forecasting Volatility in Copper Price Returns with GARCH Models. Unpublished thesis. Lund University.

Goyal, A. (2000). Predictability of stock return volatility from GARCH models. Anderson Graduate School of Management, UCLA, Los Angeles, CA, May.

Grek, Å., \& Mantalos, P. (2014). Forecasting accuracy for ARCH models and GARCH $(1,1)$ family - Which model does best capture the volatility of the Swedish stock market?.

Guo, H. (2012). Estimating Volatilities by the GARCH and the EWMA model of PetroChina and TCL in the Stock Exchange Market of China.

Hou, A., \& Suardi, S. (2012). A nonparametric GARCH model of crude oil price return volatility. Energy Economics, 618-626. https://doi.org/10.1016/j.eneco.2011.08.004

Hwang, S., \& Satchell, S. E. (1998). Implied Volatility Forecasting: A Comparison of Different Procedures Including Fractionally Integrated Models with.

Lama, A., Jha, G., Gurung, B., Paul, R. K., \& Sinha, K. (2016). VAR-MGARCH Models for Volatility Modelling of Pulses Prices: An Application.

Mcleod, A. I., \& LI, W. K. (1983). Diagnostic checking ARMA time series models using squared-residual autocorrelations. Journal of Time Series Analysis, 4, 269-273. https://doi.org/10.1111/j.1467-9892.1983.tb00373.x

Minović, J. (2017). Application and diagnostic checking of univariate and Multivariate GARCH Models in Serbian financial market. Economic analysis, 41, 73-87.

Mokoma, T. J., \& Moroke, N. D. (2014). Exchange rate volatility in South Africa: A comparative analysis of the ARCH and GARCH models. Unpublished thesis, North West University. 
Mwita, P. N., \& Nassiuma, D. K. (2015). Volatility Estimation of Stock Prices using Garch Method. Kabarak Journal of Research \& Innovation, 3, 48-53.

Nelson, D. B. (1991). Conditional heteroskedasticity in asset returns: A new approach. Econometrica: Journal of the Econometric Society, 347-370.

Nelson, D. B., \& Cao, C. Q. (1992). Inequality constraints in the univariate GARCH model. Journal of Business \& Economic Statistics, 10, 229-235. https://doi.org/10.1080/07350015.1992.10509902

Obeng, P. (2012). Testing the predictive power of various exchange rate models in forecasting the volatility of exchange rate. Doctoral dissertation, Lethbridge, Alta: University of Lethbridge.

Predescu, O. M., \& Stancu, S. (2011). Portfolio Risk Analysis using ARCH and GARCH Models in the Context of the Global Financial Crisis. Theoretical \& Applied Economics, 18.

Restrepo, E., \& Isabel, M. (2012). Estimating Portfolio Value at Risk with GARCH and MGARCH models. Perfil de Coyuntura Económica, (19), 77-92.

Satchell, S., \& Knight, J. (2011). Forecasting volatility in the financial markets. Elsevier.

Sjöholm, S. (2015). Heteroscedasticity Models and their Forecasting Performance.

Sohn, B. (2010). Stock market volatility and trading strategy based factors. Unpublished paper, Georgetown University.

Teräsvirta, T. (2009). An introduction to univariate GARCH models. Handbook of Financial Time Series. Springer. https://doi.org/10.1007/978-3-540-71297-8_1

Wang, Y., \& Wu, C. (2012). Forecasting energy market volatility using GARCH models: Can multivariate models beat univariate models?. Energy Economics, 2167-2181. https://doi.org/10.1016/j.eneco.2012.03.010

Wei, Y., Wang, Y., \& Huang, D. (2010). Forecasting crude oil market volatility: Further evidence using GARCH-class models. Energy Economics, 1477-1484. https://doi.org/10.1016/j.eneco.2010.07.009

Zakoian, J. M. (1994). Threshold heteroskedastic models. Journal of Economic Dynamics and control, 18, 931-955. https://doi.org/10.1016/0165-1889(94)90039-6

\section{Copyrights}

Copyright for this article is retained by the author(s), with first publication rights granted to the journal.

This is an open-access article distributed under the terms and conditions of the Creative Commons Attribution license (http://creativecommons.org/licenses/by/4.0/). 